\title{
A educação como ferramenta na prevenção e combate ao Cyberbullying
}

\author{
Denise Pires da Silva \\ Instituto Federal de Educação, Ciência e Tecnologia do Rio Grande do Sul (IFRS) - Campus Porto Alegre \\ (denisepires.sb@hotmail.com)
}

\begin{abstract}
Resumo: O avanço tecnológico e a popularização da internet revelam uma variação do bullying, o bullying virtual, (cyberbullying) que tem desafiado escola e sociedade, prejudicando o rendimento escolar e o bem-estar dos alunos. O presente trabalho trata-se, metodologicamente, de uma pesquisa-ação realizada no segundo semestre de 2017, com professores e alunos de três turmas do 6o ano e uma do 9ำ ano da Escola Estadual de Ensino Fundamental João Goulart da cidade de São Borja/ RS. A pesquisa constituiu-se em entrevista coletiva com os docentes e questionário estruturado online com os discentes. Os resultados revelaram que $30 \%$ dos alunos já foram vítimas de alguma ofensa virtual e $20 \%$ já se envolveram como agressores. Tais práticas ainda não são conhecidas por alguns professores, o que reforça a necessidade de abordar essa questão no âmbito escolar. Para orientação e prevenção a situações de cyberbullying foram realizadas peça teatral e palestra, criação de uma fanpage e o lançamento da campanha "\#bullyingnadaave", essas ações foram desenvolvidas em parceria com a Equipe de Estratégia de Saúde da Família "ESF 08", instituição comprometida com o Programa Saúde na Escola.
\end{abstract}

Palavras- chave: Bullyin; Cyberbullying; Educação.

\section{Education as a tool to prevent and combat Cyberbullying}

Abstract: Technological advancement and the popularization of the Internet reveal a variation of bullying, virtual bullying (cyberbullying) that has challenged school and society, hampering school performance and student well-being. The present work deals, methodologically, with an action research carried out in the second half of 2017, with teachers and students from three classes of the 6th grade and one from the 9th grade from the João Goulart State School of Basic Education in the city of São Borja / Brazil. The research consisted of a collective interview with the teachers and a questionnaire structured online with the students. The results revealed that $30 \%$ of the students are already victims of some virtual offense and $20 \%$ have already become involved as aggressors. Such practices are not yet known by some teachers, which reinforces the need to address this issue in the school context. For the orientation and prevention of cyberbullying situations, theatrical play and lecture, creation of a fanpage and the launching of the "\#bullyingnadaave"("bullying, no way!") campaign were carried out. These actions were developed in partnership with the Family Health Strategy Team "ESF 08", institution committed to the School Health Program.

Keywords: Bullying; Cyberbullying; Education.

\section{INTRODUÇÃO}

O mau uso dos recursos tecnológicos e da internet, especialmente entre adolescentes, facilitou o surgimento de uma variação do bullying, o bullying virtual, denominado cyberbullying. O cyberbullying difere-se do bullying pelo fato da agressão não ocorrer necessariamente entre pares, como de aluno para aluno. Segundo Lima et.al., (2012, p. 3) "isso ocorre porque no ciberespaço as pessoas, na maioria das vezes, não expõem suas identidades reais". 
Essa sensação de anonimato que o mundo virtual proporciona sugere que a conduta de crianças e adolescentes quanto ao acesso a internet ocorra sob supervisão e orientação de pais e professores, para que se previna a exposição do jovem a situações de violência como o cyberbullying. Com efeito, ainda mais devastador do que o bullying comumente vivenciado no ambiente escolar, o cyberbullying rompe com o espaço físico, fazendo que as difamações e/ou insultos tenham impacto ainda maior na vida da vítima.

Os problemas vão desde a queda no rendimento escolar, ao isolamento e depressão. O que evidencia que escolas e famílias desenvolvam competências e destaca a necessidade de políticas públicas de regulação e intervenção diante do fenômeno (PALFREI e GASSER, 2011; WALKER, 2010 apud WENDT e LISBOA, 2013).

Reconhecido como um ato grave, negligenciado muitas vezes pela comunidade escolar, a intimidação sistemática (bullying) exigiu do Estado a criação de leis para seu enfrentamento.

A nível federal, em fevereiro de 2016, entrou em vigor a lei 13.185 que instituiu o programa de combate ao bullying em todo território nacional, atribuindo às escolas, clubes e agremiações recreativas o dever de assegurar medidas de conscientização, prevenção, diagnose e combate à violência e à intimidação sistemática (bullying) (BRASIL, ART. 5ำ 2015). Além de produzir e publicar relatórios bimestrais das ocorrências de bullying nos estados e municípios para planejamento das ações (BRASIL, ART. 6ํ, 2015).

No âmbito estadual, em 28 de junho de 2010, foi sancionada a lei 13.474, que dispõe sobre o combate da prática de "bullying" por instituições de ensino e de educação infantil, públicas ou privadas, com ou sem fins lucrativos. A lei reconhece

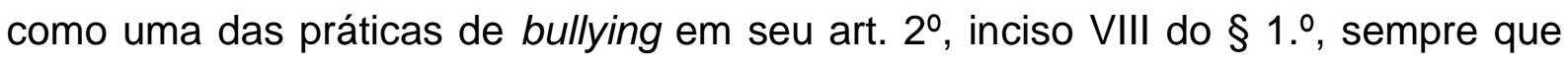
repetidas, denominando de cyberbullying: o "envio de mensagens, fotos ou vídeos por meio de computador, celular ou assemelhado, bem como sua postagem em "blogs" ou "sites", cujo conteúdo resulte em exposição física e/ou psicológica a outrem" (RIO GRANDE DO SUL, 2010).

O Art. $3^{\circ}$ da lei 13.474 define como objetivos da política "antibullying" no âmbito de cada instituição, dentre outros: 
I - reduzir a prática de violência dentro e fora das instituições de que trata esta Lei e melhorar o desempenho escolar;

II- promover a cidadania, a capacidade empática e o respeito aos demais;

III- disseminar conhecimento sobre o fenômeno "bullying" nos meios de comunicação e nas instituições de que trata esta Lei, entre os responsáveis legais pelas crianças e adolescentes nelas matriculados (RIO GRANDE DO SUL, 2010).

As ocorrências de violência entre alunos não devem ser consideradas brincadeiras próprias da idade. Conforme Casado (2011), o cyberbullying reflete todas as formas de intolerância transferida do mundo real para o mundo virtual, com exceção das práticas de violência física. Reconhecendo a importância de abordar questões como bullying, cyberbullying e excesso de exposição nas redes sociais, o presente estudo objetivou promover ações no ambiente formal de ensino e no ciberespaço, a fim de orientar e prevenir situações de violência virtual, estabelecendo parceria entre escola e instituição comprometida com questões de interesse ao trabalho educativo.

\section{O PAPEL DA EDUCAÇÃO NO ENFRENTAMENTO DO CYBERBULLYING}

A escola não deve estar alheia aos acontecimentos que perpassam seu ambiente, uma vez que as relações vivenciadas pelos alunos impactam o processo de ensino- aprendizagem. Para Outeiral (2008, p. 34) "conforme o ambiente que 0 adolescente vivencia, teremos um aprendizado prazeroso e propício, ou distúrbios de conduta e/ou de aprendizagem".

Com o avanço tecnológico e a popularização da internet, as relações presenciais passam a dividir a atenção de pais e educadores com as relações estabelecidas no ambiente virtual, especialmente em relação às redes sociais, por fazerem parte do cotidiano dos adolescentes, que nem sempre têm o discernimento de utilizá-las com segurança e responsabilidade. O que ratifica o exposto por Tognetta e Bozza (2012) que apontam que a maior incidência da prática de cyberbullying está entre adolescentes e jovens em idade escolar.

No processo de enfrentamento e prevenção ao bullying virtual, cabe a educação, tanto a atribuída à escola, quanto a de responsabilidade da família, a determinação de limite à criança e ao adolescente. Outeiral (2008) afirma que o 
limite cria um espaço e um tempo protegido, no qual o adolescente pode exercer sua espontaneidade e criatividade sem receio e riscos, tanto para si como para os outros. Situações como o cyberbullying desafiam a escola em sua atribuição de oportunizar ao aluno um ambiente agradável e acolhedor para a construção do conhecimento.

Dessa forma, a escola, compreendida aqui como ambiente formal de ensino, não está isenta desta responsabilidade, pois, a educação, também objetiva a construção da cidadania e a formação dos valores do indivíduo, conforme Luz (2013, p. 31) "nada mais importante para o ser humano do que sentir-se aceito, amado, querido e respeitado".

Moran (2013) afirma que tão importante quanto o conhecimento intelectual é o equilíbrio emocional, o desenvolvimento de atitudes positivas diante de si mesmo e dos outros, o aprender a colaborar e a viver em sociedade e em grupo.

Atitudes de solidariedade, respeito, repúdio a injustiças são listados pelos Parâmetros Curriculares Nacionais- PCNS (1998) como um dos objetivos do ensino fundamental, portanto não devem ser negligenciadas pela escola, que exerce papel importante na formação da cidadania, que se faz, antes de mais nada, pelo seu exercício (PCNS ,1998, p.41).

Ao orientar a criança ou adolescente sobre o uso consciente e responsável da internet oportuniza-se ao indivíduo o exercício de seus direitos e deveres, inerentes a cidadania, uma vez que, o ciberespaço possibilitou as relações interpessoais, 0 que sugere que essas relações sejam pautadas por regras de conduta, que regulam o padrão e comportamento desejado e o inadmissível, para a convivência harmônica em sociedade. Para Massad, Wanzinack, (2015 p.149)

A internet atualmente vem assumindo um papel de extrema
importância na vida de crianças, jovens e adolescentes. Diante
desse fato, cada vez mais é preciso assumir as discussões
sobre as regras de conduta para o bom uso desta ferramenta.
A internet bem como suas ferramentas precisa ser explorada,
porém para que isto aconteça com coerência, faz-se
necessário à intervenção e esclarecimento por parte dos pais,
mães e profissionais da educação envolvidos neste processo.

Referindo- se ao uso da tecnologia por parte dos discentes Fante e Pedra apud Arcie et.al., (2016), mencionam que a escola desempenha o papel de refletir 
com seus alunos a utilização de forma responsável e ética dos recursos tecnológicos, alertando sobre os riscos do cyberbullying.

Por se tratar de um tema transversal, definido pelos PCNS (1998) como questões importantes, urgentes e presentes sobre várias formas na vida cotidiana, o cyberbullying deve ser encarado como um problema presente na vida dos alunos. Assim, cabe à escola definir diretrizes de enfrentamento e combate a esta prática. Estabelecer parcerias com instituições comprometidas com questões que abordam valores referentes à cidadania e desenvolvem atividades de interesse para o trabalho educativo torna-se uma contribuição valiosa (PCNS, 1998).

\section{METODOLOGIA}

Este trabalho trata-se de uma pesquisa do tipo descritiva, que segundo Gil (2002, p.42) "tem como característica mais significativa a utilização de técnicas padronizadas de coletas de dados"; pode ser caracterizada como pesquisa- ação, pois "[...] exigiu o envolvimento ativo do pesquisador e a ação por parte das pessoas envolvidas no problema" (GIL, 2002, p.55). A pesquisa teve, como população e amostra, 9 professores e 53 alunos de três turmas do $6^{\circ}$ ano e uma do $9^{\circ}$ ano da Escola Estadual de Ensino Fundamental João Goulart, composta por estudantes na faixa etária entre 11 e 15 anos. A escolha das turmas se deu em virtude do horário disponível para as ações e por contemplar o Ensino Fundamental, de acordo com a literatura consultada, ocorre maior incidência de bullying (LOPES NETO, 2005; MOURA, 2011; OLIVEIRA, 2015 apud AMARAL, 2016).

Para verificar a percepção e conhecimento que professores e alunos possuem do cyberbullying, foram ouvidos os docentes em entrevista coletiva e, posteriormente, foi aplicado questionário estruturado online aos discentes.

Os professores foram convidados a contribuir para a elaboração do questionário destinado aos alunos, por conhecerem a realidade da escola e o perfil dos envolvidos com a pesquisa. Foi criado um questionário online anônimo composto por 15 questões objetivas, estruturado em dois blocos. O primeiro bloco destinado a caracterizar os participantes quanto ao sexo, idade, perfil de acesso à internet e verificar o conhecimento dos alunos sobre o cyberbullying. $O$ segundo, elaborado com intuito de conhecer o comportamento online dos estudantes e averiguar se há o envolvimento dos participantes em situações de cyberbullying. 
A aplicação da pesquisa aos alunos se deu no laboratório da escola, da seguinte forma:

a. Explicação do teor da pesquisa;

b. Explicação da necessidade dos pais ou responsáveis assinarem o termo autorizando a participação do aluno;

c. Aplicação do questionário online mediante entrega do termo de livre esclarecido (TCLE) assinado pelo responsável legal do menor.

Como ação paralela à pesquisa, foi apresentada uma palestra e peça teatral, abordando o bullying, cyberbullying e excesso de exposição nas redes sociais. Essa ação foi realizada em parceria com um grupo de teatro amador da comunidade local e com equipe de Estratégia de Saúde da Família1-“ESF 08”, que faz parte do programa saúde na escola².

Concomitante a ação foi divulgada a fanpage ${ }^{3}$ e a hashtag "\#bullyingnadaave". "O uso da hashtag (\#) diante de uma ou mais palavras aglutinadas, permite que o conhecimento seja "etiquetado", fazendo com que os usuários possam seguir informações específicas sobre um assunto e/ ou evento (SILVA; VIEIRA; SCHNEIDER, 2010, p. 5).

A fanpage disponibilizou informações referentes ao bullying, cyberbullying e uso seguro da internet, bem como permitiu aos alunos postagens com mensagens educativas de combate ao cyberbullying. O que confirma o exposto por Costa e Ferreira (2012) quando mencionam que as redes sociais podem ter finalidades pedagógicas, pois possibilitam estudo em grupo, troca de conhecimento e aprendizagem colaborativa.

A Análise dos dados se deu por uma abordagem quali-quantitativa. Conforme Minayo (2012, p.22): "entre as duas abordagens há uma oposição complementar,

\footnotetext{
$1 \quad$ Estratégia de Saúde da Família (ESF) é uma equipe multiprofissional, que possui dentre suas atribuições realizar ações de educação em saúde a população adstrita, conforme planejamento da equipe.

2 Programa Saúde na Escola (PSE) é uma estratégia de integração da saúde e educação para o desenvolvimento da cidadania e da qualificação das políticas públicas brasileiras.
}

Fanpage ou página de fãs é uma página específica dentro do Facebook direcionada para empresas ou marcas 
que quando bem trabalhada teórica e praticamente, produz riqueza de informações, aprofundamento e maior fidedignidade interpretativa". O que possibilitou verificar o conhecimento que professores e alunos têm acerca do cyberbullying e o engajamento nas ações realizadas.

\section{RESULTADOS}

Os resultados da pesquisa-ação foram organizados em quatro subcategorias, que demonstram a percepção dos professores, o conhecimento dos alunos em relação ao cyberbullying, comportamento online dos discentes e o engajamento dos envolvidos nas ações propostas, apresentadas a seguir.

\section{O cyberbullying na percepção dos professores da E. E.E João Goulart/ RS}

Foram ouvidos em entrevista coletiva, (7) sete dos (9)nove professores que lecionam no 6ำ e 9a ano, na Escola Estadual de Ensino Fundamental João Goulart, dos quais, todos souberam caracterizar o cyberbullyng, mas somente (2) dois disseram ter ciência do envolvimento de seus alunos em situações de bullying virtual, especialmente no que diz respeito ao compartilhamento de fotos ou vídeos, nos quais expunham seus pares a situações constrangedoras. Também revelaram não ter conhecimento do desfecho dos casos, restringindo a observação suspeita deste comportamento entre os alunos nas instalações externas da escola, nas aulas de educação física ou no horário de intervalo, visto que, nestes lugares, os discentes têm maior liberdade para o uso de celulares.

Cinco (5) dos professores entrevistados, disseram desconhecer a existência de cyberbullying entre os alunos, no entanto, já presenciaram o bullying tradicional através de apelidos ou por violência física. O que corrobora que o bullying está presente nas escolas e se constitui como um dos principais tipos de violência enfrentados por crianças e jovens (MASSAD, WANZINACK, 2015; LOPES NETO, 2005; TOGNETTA, BOZZA, 2012).

Os docentes foram unânimes em reconhecer a importância do debate sobre o cyberbullying e excesso de exposição nas redes sociais no âmbito escolar.

A tabela 1 transcreve a entrevista realizada com os docentes que foi conduzida de maneira que permitiu aos entrevistados conceituar cyberbullying, relatar sua percepção sobre o envolvimento dos alunos do $6^{\circ}$ e $9^{\circ}$ ano em situações 
de agressão virtual e ouvir suas considerações sobre a importância de refletir com os alunos sobre esse tema e abordar o excesso de exposição em redes sociais.

Tabela 1- Entrevista com os docentes

\begin{tabular}{|c|c|}
\hline \multicolumn{2}{|c|}{ Perguntas } \\
\hline Conceitue cyberbullying: & Respostas \\
\hline Professor 1 e 2 & $\begin{array}{l}\text { Variação do bullying; praticado por } \\
\text { intermédio das tecnologias em que a } \\
\text { identificação do agressor é dificultada pelo } \\
\text { anonimato. }\end{array}$ \\
\hline Professor 3 e 4 & $\begin{array}{l}\text { Cyberbullying é o bullying virtual, intencional } \\
\text { e recorrente que pode causar sérios danos } \\
\text { psicológicos à vítima. }\end{array}$ \\
\hline \begin{tabular}{|l|} 
Professor 5, 6 e 7 \\
\end{tabular} & $\begin{array}{l}\text { O cyberbullying é a intimidação sistemática, } \\
\text { praticada pelo envio de fotos ou vídeos, e- } \\
\text { mails ou assemelhado. }\end{array}$ \\
\hline \multicolumn{2}{|c|}{$\begin{array}{l}\text { Vocês já perceberam o envolvimento dos alunos do } 6^{\circ} \text { e } 9^{\circ} \text { ano em situações de } \\
\text { cyberbullying? }\end{array}$} \\
\hline Professor 1 & $\begin{array}{l}\text { "Não. É comum acontecer o bullying } \\
\text { propriamente dito". }\end{array}$ \\
\hline Professor 2 & $\begin{array}{l}\text { Complementou a resposta do professor } 1 \\
\text { dizendo: "inclusive um aluno específico } \\
\text { agride os colegas com frequência". }\end{array}$ \\
\hline Professor 3 & $\begin{array}{l}\text { "Sim, certa vez em aula um aluno comentou } \\
\text { que havia recebido uma foto exibindo } \\
\text { "nudes" } 4 \text { de uma adolescente de outra } \\
\text { escola". }\end{array}$ \\
\hline \begin{tabular}{|l|} 
Professor 4 \\
\end{tabular} & $\begin{array}{l}\text { Comentou que percebe que nas redes } \\
\text { sociais alguns alunos acabam por } \\
\text { compartilhar fotos atribuindo apelidos } \\
\text { pejorativos a outros colegas. Ressaltou } \\
\text { também que os alunos tem liberdade para } \\
\text { acessar as redes sociais no período de } \\
\text { intervalo. }\end{array}$ \\
\hline
\end{tabular}

$4 \quad$ Nudes vem do inglês nude que significa nu. 


\begin{tabular}{|c|c|}
\hline Professor 5, 6 & $\begin{array}{l}\text { Afirmaram não ter conhecimento do } \\
\text { envolvimento dos seus alunos em situações } \\
\text { de cyberbullying. }\end{array}$ \\
\hline Professor 7 & $\begin{array}{l}\text { Desconhece o envolvimento de seus alunos } \\
\text { em situações de cyberbullying. "O que } \\
\text { acontece é o bullying, que fica evidente pelas } \\
\text { frequentes agressões físicas e verbais } \\
\text { praticadas por alguns alunos". }\end{array}$ \\
\hline \multicolumn{2}{|c|}{$\begin{array}{l}\text { Você considera importante oportunizar a reflexão e o debate com os alunos sobre o } \\
\text { cyberbullying e excesso de exposição em redes sociais? }\end{array}$} \\
\hline \begin{tabular}{|l|} 
Professor 1 \\
\end{tabular} & $\begin{array}{l}\text { "Sim, pois ajudará a prevenir que o } \\
\text { cyberbullying aconteça". }\end{array}$ \\
\hline \begin{tabular}{|l|} 
Professor 2 \\
\end{tabular} & $\begin{array}{l}\text { "Sim, é importante orientar ao adolescente } \\
\text { sobre as consequências de suas práticas, } \\
\text { quer sejam elas presenciais ou online". }\end{array}$ \\
\hline Professor 3 & $\begin{array}{l}\text { "É um assunto relevante porque os alunos } \\
\text { passam grande parte do seu tempo } \\
\text { conectados". }\end{array}$ \\
\hline Professor 4 & $\begin{array}{l}\text { "Ė necessário debater sobre esse assunto, já } \\
\text { que os celulares e a internet popularizaram- } \\
\text { se entre os alunos". }\end{array}$ \\
\hline \begin{tabular}{|l|} 
Professor 5 \\
\end{tabular} & $\begin{array}{l}\text { "É muito importante orientar sobre o uso } \\
\text { seguro e responsável da tecnologia". }\end{array}$ \\
\hline Professor 6 & $\begin{array}{l}\text { "Sim é importante oportunizar a reflexão } \\
\text { sobre o malefício do cyberbullying e orientar } \\
\text { o aluno sobre o uso seguro da internet, a fim } \\
\text { de prevenir que o bullying virtual aconteça". }\end{array}$ \\
\hline Professor 7 & $\begin{array}{l}\text { "Considero importante ações de orientação } \\
\text { já que o adolescente torna-se vulnerável ao } \\
\text { se expor nas redes sociais sem a supervisão } \\
\text { da família." }\end{array}$ \\
\hline
\end{tabular}

Fonte: elaborada pelos autores 


\section{Caracterização Individual- Conhecimento dos alunos sobre o cyberbullying}

Dos 65 alunos matriculados nos sextos e nono ano, 53 alunos tiveram oportunidade de participar da pesquisa, pois, estavam presentes nas datas que foram entregues os termos de livre esclarecido - TCLE. Destes, 20 foram aptos a responder o questionário por apresentar o TCLE devidamente assinado pelo responsável legal.

A aplicação do questionário foi realizada em dois dias consecutivos no laboratório de informática da escola. Quanto ao sexo, a pesquisa teve $70 \%$ de participação feminina e $30 \%$ masculina. A faixa etária dos pesquisados compreende $25 \%$ entre 10 e 11 anos, 30\% entre 12 e 13 anos e $45 \%$ com idade entre 14 e 15 anos.

Quando questionados com que frequência acessam a internet, 5\% não acessam; 30\% acessam 1 hora por dia; 30\% acessam entre 2 a 4 horas por dia e $35 \%$ acessam mais de 4 horas por dia. O celular é o meio de acesso mais frequente entre $95 \%$ dos entrevistados, apenas 5\% utilizam o tablet. "Isso pode ser explicado pelo avanço tecnológico de aparelhos telefônicos e a entrada do smartphone que facilita o acesso à internet por via do celular" (SCHREIBER; ANTUNES, p. 17746, 2015). O acesso à internet é realizado em casa por $44 \%$ dos entrevistados, em casa de parentes ou amigos por $28 \%$, na escola em igual porcentagem. Nenhum dos pesquisados costuma recorrer a lanhouse para ter acesso à internet.

Comprovando a popularização dos aplicativos de mensagens instantâneas e das redes sociais entre adolescentes, 31\% dos entrevistados utilizam a internet para acessar WhatsApp ou Snapchat; 27\% Facebook ou Twitter; 24\% assistem vídeos no Youtube; $11 \%$ utilizam o Google para pesquisa e 7\% para postar e ver fotos no Instagram.

Massad e Wanzinack (2015, p. 150) mencionam que "[...] as redes sociais vêm se tornando um espaço de socialização e de trocas de conhecimento e algumas vezes de violência virtual". Desta forma, ratifica-se a importância da utilização desse espaço para orientação de jovens e adolescentes a fim de conscientizar sobre as práticas de intimidação virtual, visto que: $60 \%$ dos alunos admitiram não ter conhecimento sobre o cyberbullying; $20 \%$ afirmaram ter conhecimento, mas não souberam conceituar, outros $20 \%$ dos entrevistados, composto pelo sexo feminino, demonstraram ter conhecimento e conceituaram como bullying virtual. "Apesar de ser um problema mundial, o cyberbullying é pouco conhecido pelo grande público ou 
subestimado pelos adultos, que muitas vezes o encara como uma brincadeira de crianças" (CIPAVE, p. 28, 2015).

\section{Comportamento online dos estudantes}

Ao confrontar as ações dos discentes diante de situações de cyberbullying, os resultados demonstram que $5 \%$ compartilham ou comentam postagens ofensivas publicadas por amigos por concordar com sua atitude; 25\% apenas curtem, por considerar uma brincadeira; $25 \%$ comentam sua insatisfação com a postagem e pedem que o amigo exclua a publicação; 35\% visualizam sem tomar atitude alguma; enquanto 10\%, afirmam desfazer amizade quando deparados com tal situação.

A análise das questões identificou a existência de vítimas de cyberbullying entre os entrevistados, pois, $25 \%$ afirmaram ter sido ofendido nas redes sociais, ou recebido mensagens que os deixaram tristes, envergonhados ou com medo. Enquanto, 30\% revelaram que as ofensas aconteceram em redes sociais, internet, email ou $\mathrm{SMS}^{5}$. Sofre a frequência em que foram expostos a situações de cyberbullying, $5 \%$ revelaram que, por 5 ou mais vezes, foram criticados ou ofendidos por intermédio de redes sociais, internet, email ou SMS; $10 \%$ confirmaram ter sofrido com tal prática de 3 a 4 vezes, enquanto 15\% revelaram a ocorrência desse tipo de intimidação 1 ou 2 vezes. Cabe ressaltar que, segundo Schreiber e Antunes (2015); Tognetta e Bozza (2012) diferente do bullying presencial, os eventos virtuais podem ocorrer apenas uma vez e, ainda assim, serem caracterizados como cyberbullying devido às potencialidades da internet, visto que sua repetição se dá por si só, em meios de compartilhamentos.

Quando indagados de suas reações ao serem expostos a comentários ofensivos, sejam eles presenciais ou virtuais $45 \%$ ignoraram o fato; $5 \%$ resolveram conversar com o autor da agressão; 5\% contaram para um amigo em segredo, enquanto $10 \%$ mantiveram sigilo; outros $10 \%$ contaram para familiares e $25 \%$ nunca sofreram. Nenhum aluno solicitou à ajuda de professores, o que confirma o exposto pelos docentes entrevistados, que muitas vezes o envolvimento dos discentes em ocorrências de cyberbullying, limita-se a observação suspeita.

SMS (Short Message Service) - serviços de mensagens curtas. 
Ao marcar mais de uma alternativa, 19\% das vítimas de cyberbullying confirmaram que já tiveram fotos suas divulgadas por celular, com intuito de ofendêlos, $14 \%$ afirmaram ter sido alvos de postagem com mensagem ou comentário ofensivo. Ao serem questionados se tinham ciência de gênero e idade do agressor, $9 \%$ afirmaram ter sofrido agressão virtual causada por uma menina da mesma faixa etária, $5 \%$ relataram que foram ofendidos por uma menina de maior idade, enquanto 14\% revelaram que o autor das agressões foi um menino de maior faixa etária. Em casos de cyberbullying a identificação do autor é dificultada pela possibilidade do agressor utilizar codinomes.

A análise dos questionários demonstrou o envolvimento de alguns alunos como agressores, pois, $10 \%$ confirmaram que, várias vezes, por vários motivos, publicaram ou compartilharam foto ou vídeo de alguém com o objetivo de criticar, se vingar ou simplesmente por não gostar da pessoa; $5 \%$ revelaram ter praticado uma única vez com o objetivo de criticar; $5 \%$ alegaram ter agido uma única vez com o objetivo de se vingar.

Os resultados demonstraram que, $90 \%$ dos alunos acessam conteúdos dos quais seus pais ou familiares têm conhecimento e 10\% afirmaram que seus responsáveis desconhecem o conteúdo de seus acessos. Este fato confirma o exposto por Domingues et.al., (2016) quando menciona que "[...] os pais nem sempre acompanham os movimentos online dos filhos até que algo desagradável ocorra".

\section{Ações anti-cyberbullying}

As ações foram desenvolvidas na escola e no Facebook com o objetivo de oportunizar a reflexão e o debate, contribuindo para orientação, prevenção e combate ao cyberbullying no contexto escolar. São elas: peça teatral intitulada "Se liga galera", palestra com a coordenadora da ESF 08 e divulgação da página e hashtag "Bulliyng nada a vê".

\section{Palestra e peça teatral}

Adaptado da peça "Bullying não é Brincadeira"6, o teatro foi encenado por atores amadores, da comunidade local. A peça abordou de maneira humorada as

Disponível em: https://www.youtube.com/watch?v=jopT-W91M88 
causas do bullying na família. Entre as relações abordadas estão: relacionamento entre pais e filhos, os confrontos entre irmãos e as condutas violentas incentivadas por amigos e colegas.

O texto da peça trouxe a questão do cyberbullying que é facilitado, muitas vezes, pelo excesso de exposição nas redes sociais. O espetáculo alertou também, sobre o bullying nas escolas mencionando que a conduta de todo cidadão deve ser pautada por respeito e empatia.

$\mathrm{Na}$ sequência a coordenadora da ESF discorreu sobre 0 fato do bullying/cyberbullying ser encarado como uma questão de saúde pública. Ressaltou a importância do envolvimento dos profissionais da área da saúde e da educação, trazendo ao conhecimento do público as leis que estabelecem os programas "antibullying".

\section{Campanha "Bullying nada a vê"}

O objetivo norteador para a criação da página "Bullying nada a vê" foi desenvolver ações em redes sociais como espaço para promover campanhas anticyberbullying. Essa denominação se deu em virtude de aproximar-se da linguagem coloquial predominante entre os adolescentes. O layout da fanpage foi projetado de maneira que visualmente despertasse a atenção, comunicasse tanto a meninos quanto a meninas e transmitisse a seriedade que o assunto exige.

Imagem 1- Imagem do perfil

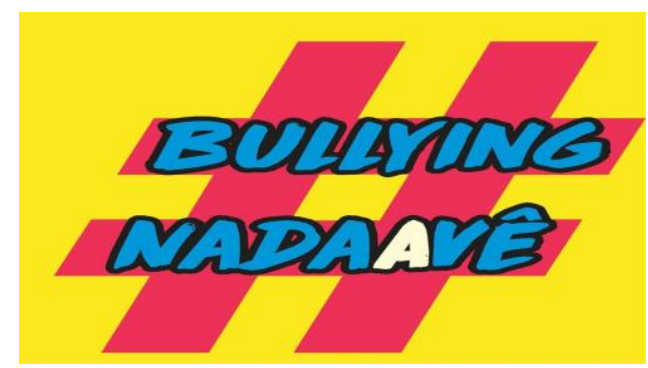

Imagem 2- Capa da página

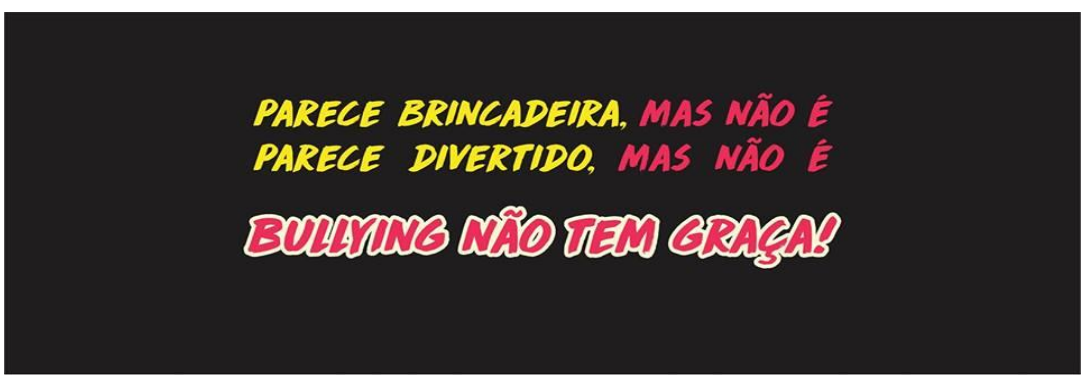


Os conteúdos disponibilizados na página vão desde a conceituação de bullying e cyberbullying, implicações legais aos agressores, dicas para o uso seguro da internet, incentivo à denúncia por parte das vítimas, até informações pertinentes para pais e professores no sentido de identificar o envolvimento dos jovens em situações de bullying/ cyberbullying.

Foi divulgado durante a peça teatral o endereço da página no Facebook @bullyingnadaave e incentivado a plateia a curtir e contribuir com postagens de conscientização e combate ao bullying e suas variações.

Quanto ao engajamento dos alunos percebe-se que o número de curtidas e visualizações na página foi superior ao número de postagens, o que pode estar relacionado à preferência dos alunos por aplicativos de mensagens como WhatsApp e Snapchat. No entanto, três alunos publicaram frases curtas seguidas da hashtag. São elas: "bullying não é brincadeira", "respeite as diferenças", "fora bullying". Uma das postagens de iniciativa de uma aluna do 9a ano mereceu destaque, pois relacionou o bullying a um problema crônico enfrentado nas escolas. Sua publicação sensibilizou o leitor para o fato que o bullying traz consequências nocivas tanto para a vítima quanto ao agressor, incentivando toda a sociedade a lutar contra essa prática.

Imagem 1 - Captura da postagem da aluna do $9^{\circ}$ ano
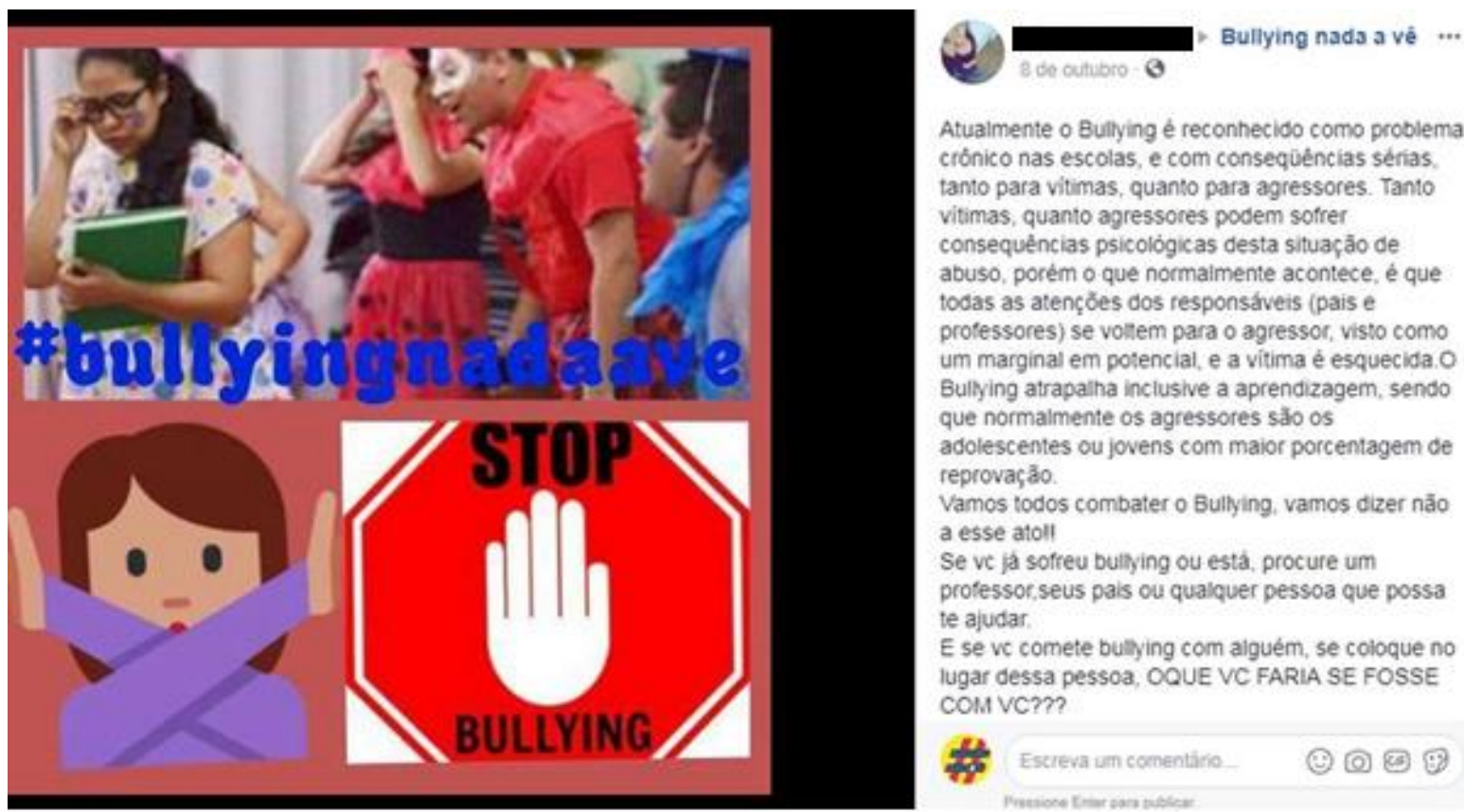


\section{CONSIDERAÇÕES FINAIS}

Apesar de ser um problema, cada vez mais frequente, que envolve, principalmente jovens e adolescentes, o cyberbullying ainda é pouco conhecido pela comunidade escolar. Por não perceber o envolvimento dos alunos em situações de bullying virtual, a escola participante da pesquisa-ação demonstrou certa indiferença com o trato a essa questão. É sabido que, para um eficiente combate ao cyberbullying, se faz necessário o envolvimento ativo dos educadores e de trabalho em rede.

Embora existam leis nos âmbitos federal e estadual que estabelecem programas "antibullying" a legislação é pouco difundida na escola. Alguns alunos sofrem calados as consequências do cyberbullying, outros agridem por motivos banais, protegidos pela sensação de anonimato.

Ao serem encenadas situações de cyberbullying foi possível perceber a identificação da plateia, o que confirma a exposição dos jovens à violência virtual, que, por falta de conhecimento não sabem conceituar e tratá-las como algo inaceitável.

Diante disso é necessário despertar nos jovens o senso de responsabilidade ao utilizar os recursos tecnológicos. As redes sociais que, por vezes, servem de cenário para a disseminação da intolerância, podem ser importantes ferramentas de interação, orientação e propagação de bons exemplos. Ações de conscientização sobre o cyberbullying foram importantes na medida em que levaram ao conhecimento dos envolvidos de que o bullying virtual não se trata de uma brincadeira. Sendo assim, para o enfrentamento do cyberbullying, são necessárias atitudes que vão desde a denúncia, ao uso responsável e ético dos recursos tecnológicos.

\section{REFERÊNCIAS}

AMARAL, N. V. O Bullying na Perspectiva do Professor: Um Estudo de Caso em São Borja (RS). 2016.66f. Trabalho de Conclusão de Curso (Curso de Ciências Humanas-Licenciatura). Universidade Federal do Pampa, São Borja.

ARCIE, J. B. et al. Cyberbullying: ações pedagógicas de caráter preventivo no contexto escolar. PSICOFAE, Curitiba, v.5, n.1, p. 89-98, Julho de 2016. 
BRASIL. Ministério da Saúde. Política Nacional de Atenção Básica. Brasília: Ministério da Saúde, 2012. (Série E. Legislação em Saúde).

CASADO, A. G. P. Cyber Bullying: violência virtual e o enquadramento penal no Brasil. Disponível em: <http://www.ambito-

juridico.com.br/site/index.php?n_link=revista_artigos_leitura\&artigo_id=10882>. Acesso em: Out. 2017

CIPAVE. Comissão interna de prevenção a acidentes e violência escolar: Cartilha Cipave. 2015

COSTA, A. M. S; FERREIRA, A. L. A. Novas possibilidades metodológicas para o ensino- aprendizagem mediados pelas redes sociais twitter e facebook. Rencima, Pelotas, v.3, n.2, p.136- 147, 2012.

DOMINGUES, M. J. C. et al. Cyberbullying: preocupação dos professores e envolvimento da escola. CONJECTURA: FILOS. EDUC, Caxias do Sul, v. 21, n. 1, p. 78-91, jan./abr. 2016.

GIL, A. C. Como elaborar projetos de pesquisa. 4. ed. São Paulo: Atlas, 2002.

LIMA, B.T.et.al. Cyberbullying: estudo introdutório sobre o conceito e sua presença no IF- Sertão Pernambucano- Campus Petrolina- PE. Disponível em: <http://www.abed.org.br/congresso2012/anais/15x.pdf>. Acesso em: Set. 2017.

LOPES NETO, A.A. Bullying: Comportamento agressivo entre estudantes. Jornal de Pediatria, Rio de Janeiro, v. 81, n.5, p.164-172. 2005. Disponível em:

<www.uff.br/saudecultura/encontros/Bullyng.pdf >. Acesso em: out. 2017.

LUZ, N. C. P. TV, educação e formação de professores [recurso eletrônico]: Salto para o Futuro : 20 anos. Rio de Janeiro : ACERP ; Brasília, DF : TV Escola , 2013.

MASSAD, C. E. F; WANZINACK, C. Violência, gênero e diversidade: desafios para a educação e o desenvolvimento. In: WANZINACK, C; SIGNORELLI, M. C. (Orgs.). 1. ed Rio de Janeiro: Autografia, 2015.

MINAYO, M. C. S; DESLANDES, S. F; GOMES, Romeu. Pesquisa Social: teoria, método e criatividade. 31. ed. Petrópolis, RJ: Vozes, 2012

MORAN, J. M; MASETTO, M. T; BEHRENS, M. A. Novas Tecnologias e Mediação Pedagógica. 21. ed. Campinas- SP: Papirus, 2013.

OUTEIRAL, J. Adolescer. 3. Ed. Rio de Janeiro: Revinter, 2008.

PARÂMETROS CURRICULARES NACIONAIS. Terceiro e quarto ciclos do ensino fundamental, temas transversais. Disponível em:

<http://portal.mec.gov.br/seb/arquivos/pdf/ttransversais.pdf>. Acesso em: Abr. 2017.

RIO GRANDE DO SUL. Lei no 13. 474, de 28 de junho de 2010. Dispõe sobre o combate da 
pratica de "bullying" por instituições de ensino e de educação infantil, publicas ou privadas, com ou sem fins lucrativos. DOE no 121, de 29 de junho de 2010.

Disponível

em:<http://www.al.rs.gov.br/legis/M010/M0100099.ASP?Hid_Tipo=TEXTO\&Hid_Tod asNormas $=54438 \&$ hTexto $=\& H i d \_I D N o r m a=54438>$. Acesso em 30 de maio de 2017.

SILVA, A. L. S; VIEIRA, E. S; SCHNEIDER, H. N. O uso das redes sociais como método alternativo de ensino para jovens: análise de três projetos envolvendo comunidades virtuais. In: IV Colóquio Internacional Educação e Contemporaneidade ISSN 1982-3657. Disponível em: <http://educonse.com.br/2010/eixo_09/e9-1a.pdf>. Acesso em: maio. 2017.

SCHREIDER, F. C. C; ANTUNES, M.C. Cyberbullying: para além dos muros das escolas. Disponível em:

<http://educere.bruc.com.br/arquivo/pdf2015/20497_11411.pdf>. Acesso em: set. 2017

TOGNETTA, L. R. P; BOZZA, T. C. L. Cyberbullying: um estudo sobre a incidência do desrespeito no ciberespaço e suas relações com as representações que adolescentes tem de si. NUANCES- Estudos sobre Educação, Campinas, V. 23, n. 24, p.162- 168, set. / dez. 2012. Disponível:

<http://revista.fct.unesp.br/index.php/Nuances/article/view/1896/1777>. Acesso em: Mai. 2017.

WANZINACK, C.; SIGNORELLI, M. C (Orgs). Violência, gênero \& diversidade: desafios para a educação e o desenvolvimento. Rio de Janeiro: Editora Autografia, 2015.

WENDT, G. W; LISBOA, C. S. M. A agressão entre pares no espaço virtual: definições impactos e desafios do Cyberbullying. Disponível em: $<$ http://www.scielo.br/scielo.php?pid=S010356652013000100005\&script=sci_abstrac t\&tlng=t>. Acesso em: Abr. 2017. 